\title{
Anthrovision
}

Vaneasa Online Journal

\section{Introduction. Digital Visual Engagements}

\section{Cristina Grasseni and Florian Walter}

\section{(2) OpenEdition \\ Journals}

Electronic version

URL: http://journals.openedition.org/anthrovision/1445

DOI: 10.4000/anthrovision. 1445

ISSN: 2198-6754

\section{Publisher}

VANEASA - Visual Anthropology Network of European Association of Social Anthropologists

\section{Electronic reference}

Cristina Grasseni and Florian Walter, «Introduction. Digital Visual Engagements », Anthrovision [Online], 2.2 | 2014, Online since 31 December 2014, connection on 22 September 2020. URL : http:// journals.openedition.org/anthrovision/1445; DOI : https://doi.org/10.4000/anthrovision.1445

This text was automatically generated on 22 September 2020

(c) Anthrovision 


\title{
Introduction. Digital Visual Engagements
}

\author{
Cristina Grasseni and Florian Walter
}

1 Do digital media formats enable new conceptual and collaborative practices? How do they allow us to challenge cinematic conventions or habitual understandings of the spatio-temporal arrangements of both ethnographic narrative and analytic insight? To what avail? This special issue is the result of conversations initiated around these questions on occasion of a co-convened panel at the Manchester IUAES conference in August 2013 (Evolving humanity, emerging worlds). Cristina Grasseni and Florian Walter called for reflections on methodological innovation in the realm of "digital visual engagements", taking stock of existing notions such as those of "collaborative ethnographic film work"1, "skilled visions" (Grasseni 2007) and "transcultural partnership" (Walter 2012). ${ }^{2}$ The authors that we introduce here critically engage with these questions, assessing whether narrative and analysis cannot in fact be complementary aspects of visual engagement. They re-incorporate so to speak the nondigital, the non-virtual materiality of visual engagements in their own understandings of the practice of anthropological fieldwork and film-work.

2 All of the contributions represent examples of different ways of interpreting what "collaborative film-making" (Elder 1995) means for the practicing anthropologist today. Some of our authors decided to produce "non films" (Battaglia, this issue), others uploaded a number of different documents and audio-visual texts on a website, so as to facilitate a "navigation" of the field site that should somehow evoke the author's own first encounters with it, and enable the viewers a degree of epistemic liberty (Ramella, this issue). Some others allowed their ethnographic film production to proliferate, making more than one film to be viewed at the same time about one topic, so as to reproduce contrasting viewpoints and their spatial and political fragmentation, using split-screen projection to make such hiatus palpable and non-negotiable for the viewers (Köhn, this issue).

3 Collective representation and practices of counter-visuality feature prominently in current visual research. Nicolas Mirzoeff (2011) for example has recently proposed the 
idea of narrating a "counterhistory" of visuality as a way of de-centering and actively interrogating given, established, even banal, and certainly hegemonic "ways of seeing" (Berger 1972). While on the one hand this agenda is not new, there have been contemporary developments regarding its purchase on the actual capacity of digital media to create "counter" practices of representation and interaction (see for example Favero 2013 on interactive documentaries or i-docs). It can also be debated whether digital media are per se participatory, and further, whether participatory digital media are per se politically engaging. In the face of proliferating "geomedia" that crossreference live personal data, social networks, location, spatial navigation, and increasingly visualization layers (Lapenta 2011), does it make sense to talk about digital visual engagement rather than immersion in digital visual environments?

4 In response to this challenge, we would like here to voice at least some of the many dilemmas and hurdles, choices and possibilities that face the ethnographer as a visual practitioner. We envisage such practice as one of broker and mapper - even of designer of spaces and platforms, formats and temporalities for multi-vocal representation. All the authors in this special issue stress the importance of using multi-sensory, multilinear and multi-format media, in order to be both as true as possible to the complexity of fieldwork experience (including the power imbalances entailed in any act of representation) and to enable transcultural understandings.

5 As Grasseni (2007) proposed through the notion of "Skilled Visions", any "schooling of the eye" tells us about the hegemonic discourse of the contexts in which it is implemented. The ethnographic focus of this issue is the ambivalent practice of competent visual knowledge in representing others and self through "digital visual engagement". Classifying at first encounter, just as much as being recognized and categorized, is part and parcel of an everyday ecology of culture for most persons' daily social life. How is this then mobilized and questioned, if at all, by the availability of so many means of refraction and self-narration (even self-stereotyping)? We would like to test the idea that interactive, multimodal and multilayer productions encourage interdisciplinary cooperation and participative research. Therefore we invited contributions to narrate their own engagement in stylistic and methodological experimentations based on active visual-anthropological fieldwork.

In the panel title, we evoke the "atlas" as a shorthand for an assemblage of heterogeneous formats, documents and traces that at once quite literally frames them and arranges them in a conceptual map of links, lineages, borrowings, contaminations and inheritances. The idea of the atlas comes from Aby Warburg's tables (Warburg 2003). Warburg's Mnemosyne Atlas was an "atlas" of pictures of many kinds and formats, including postcards and sketches. It was both a didactic support (the predecessor of power point?) and an epistemic space: a series of tables (physical wooden boards) that worked as posters, gathering heterogeneous materials in one space. Mnemosyne was Warburg's unfinished attempt at visualizing iconology (a science, a logic and a lineage of images) in art history.

Crucially, the atlas format embodies a non-linear narrative, namely a (potentially infinite) sequence of (potentially infinite) bi-dimensional spaces within which (potentially infinite) cross-references can be established and highlighted, made or unmade. Each table could have added details, feedback arrows, or be linked to a number of others. Our contemporary idea of digital mapping, of layering, and even of 
"lateral" thinking, is akin to this artisanal but visionary attempt to physically arrange traces and lineages of collective iconographic memory. ${ }^{3}$

The Atlas is not exhaustive, but thematic and augmentable (Zumbusch 2010). We evoke the atlas to gesture both at the anthropological ambition for the overview and at its capacity for ironic distancing from hegemonic visions - deconstructing stereotypes by embedding them in a history of links, quotations, copies, borrowings, and juxtapositions. Can non linear models negotiate and refract the power imbalance embodied in the act of representation?

We invite anthropologists to compare and consider complementary, sometimes competing tools that "afford" different theoretical capacities, in a Gibsonian sense. Psychologist of perception James J. Gibson is often quoted in anthropology after he was often championed in Tim Ingold's writing on the anthropology of the environment through his concept of affordance as the capacity of a given niche to enable and indeed encourage certain types of animal activity, making use of spatial arrangement, conditions of light, type of materials, sensory endurance or pleasantness. By extension, every spatial arrangement also allows (affords) certain types of conceptual and relational practices. Namely: it allows and invites them to emerge through appropriate spaces and technologies (Ingold 2000, Gibson 1979).

10 As a result of this interrogation, ours is a call for anthropologists to think about the implications of the ways in which they craft their (visual) narratives and how they arrange their research materials: for instance, through online archives that can annotate audio, video, text, and still images, or through multimedia publishing formats. This, too, is a work for visual affordance - the opening up of an epistemic space in which links and sequences become thinkable and manageable conceptually.

11 Thus in this issue Steffen Köhn discusses the "potential offered by contemporary exhibition practices for the dissemination of anthropological knowledge", insisting on the paucity of spatial and temporal arrangements of ethnographic screenings in the form of a split-screen installation. Köhn's viewing arrangement allows for multiple viewpoints to be appreciated at one and the same time, while disorienting the expectation of a linear temporal development limited to one location only. Both observational and multi-sited, the split-screen installation also preserves its cumbersome materiality as an exhibition space, which needs to be physically entered, dwelled in, and left behind.

12 Anna Lisa Ramella presents her interactive web project as an attempt at arranging her own and the residents (or rather travellers') model and knowledge of the Malian part of the former Dakar-Niger Express railway line in an open-ended, de-hierarchized mode. Through her multimedia project La Vie du Rail, she seeks to open up an interactive, intersubjective, and participatory space in which plural and competing media representations can coexist. Her concern is not to pre-scribe a narrative or a preferential spatial orientation. Containing the hierarchy between her own footage and the materials collected in the field (thus reducing the fieldworker's authority), however, does not reduce the authoriality of the project itself.

13 Giulia Battaglia hijacks the hegemony of the film-maker's authority in her own participatory film settings in India - where the participation includes both the role of the subject and the active say of the audience - relinquishing authoriality in favor of open-ended conversations in and about her ethnographic presence behind the camera. Through the concept of 'non-film', Battaglia rethinks the tacit and one-directional 
relationships between film-maker and audience, as well as between film-maker and film-'subjects'. She points to the televisual canon that implicitly frame such relations, and questions the very feasibility of collaboration and participation in film-making projects, which are expected to be author- and authority-driven, even by the very participants whom one strives to empower.

Based on her recent fieldwork in Boston, Cristina Grasseni proposes the 'atlas' as a conceptual metaphor and as a complement to montage, through which multiple voices can be inter-woven into ethnographic filmmaking. Striving to take into account the multiplicity and abundance of audio-visual documentation available in the age of in the age of social media, the 'atlas' is borrowed from Warburg's experimentation with iconographic bricolage as a way of eliciting icono-logics: lineages, traces, and sediments come to perspicuous overview when they are properly arranged in space - which of course detracts from their narrative capacity as it forces all the relevant items exist in a space of suspended temporality, where only their reciprocal affinity becomes relevant. This space of interconnections - which digital databases make potentially infinite however feeds into the analytical depth of our anthropological understandings of the soundscapes and sightscapes we engage with: in this case, a festive celebration in Boston's Little Italy.

Nadine Wanono and Gilles Remillet present their collaborative research on how open access software can be used to create multimedia presentation platforms that allow text and media to be "read and watched" in the same breath, challenging the page and the frame as the only two viable spatio-temporal arrangements for the flow of epistemic and ethnographic engagements. They also raise the important issue of expertise and power: should the visual ethnographer be a "coder", too? How can we remind ourselves of the constantly present issues of power and control over data storage, flow and exchange that new apparatuses both embody and reproduce?

The issue of power and visual hegemony is cogent to our anthropological sensibilities: in the $21^{\text {st }}$ century most of the information people gather and pass on are to an extent visual ones. Writing itself is still in many ways an inaccessible medium to many groups. Televised images are in a sense the world canon. However, an increasingly multiplatform corporate world, which hides the sources of its own media power, constructs a hegemonic cultural memory that consists of the privileged perspectives - often white, male, and middle-class imaginaries - of colonial times. On the one hand, their theorizations are hardly accessible to the non-academic audiences they are concerned with. On the other hand, their representations can hardly connect to the lived realities of the actors involved - because of their authoritative, non interactive nature. It has been argued that Western "representationalism" creates cultural differences, exotifying instead of triggering transcultural modes of understandings (Walter 2012). While collaborative ethnographic film-making can develop empathy towards specific protagonists in terms of an "ethnography of the particular" (see Abu-Lughod 1986), anthropologists are increasingly interested in experimenting with the many epistemological practices that might help establish a "democracy of the senses" (Bull and Les Back 2003: 2), in which the tele-visual is hijacked from being the bidimensional, mono-directional sense of a colonial project (see Foucault 1975, Ong 1991).

The call to explore innovative media forms as platforms for co-theorization would not be consistent if we did not look at non-linear forms of representation and mediation as a practice of democratization of knowledge. Some of these papers are specifically 
concerned with re-integrating traditionally invisible voices - those of the subjects and the objects of research - into anthropological representation, also for broader audiences. Some of these works have been devised as experimental knowledge practices or as art installations, and have been shown in museums, exhibitions and film festivals. Wanono and Remillet as well as Battaglia, for instance, question the normative practice of writing and filming cultural otherness, and try to offer expressive and political alternatives through collaborative and experimental methodologies.

Among models of new forms of collaboration that can be developed through digital visual engagement, are what Florian Walters calls "transcultural partnership media" (Walter 2012). The key concept entailed in this expression is the possibility of developing visual collaborations, and how this entails an impact on transcultural processes of understandings. Walter argues for the introduction of the term partnership as part of the methodological tool-kit of a (visual) anthropologist so as to envision a transgression of the boundaries of anthropology. The practice of partnership both triggers and heightens transcultural processes of understanding. In particular the poetical dimensions of culture can be made visible or tangible in film only with the active participation of the protagonists. Transcultural partnership media is defined as a bricolage of different styles of montage that are conducive to the greatest possible amount of shared collaboration over multiple layers of materials (as illustrated in Figure 1).

Figure 1: Interactive Film

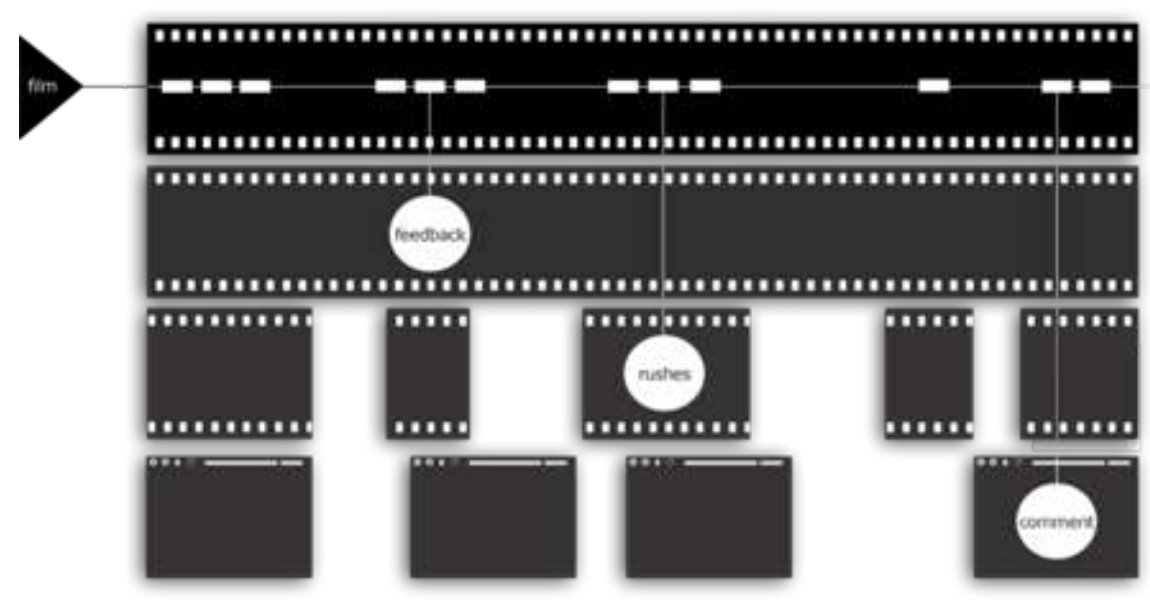

In this example Transcultural Partnership Media is basically a linear but interactive film. The audiences can access feedback sequences, the original rushes and leave comments while watching the movie.

(c) Florian Walter

19 The proposal is to enhance the form of media itself, from a pure audiovisual and linear representation toward a multidimensional media in which film-making could be but one part of many representational actions and refractions, as illustrated in figure 2 . 
Figure 2: Non-Linear Film

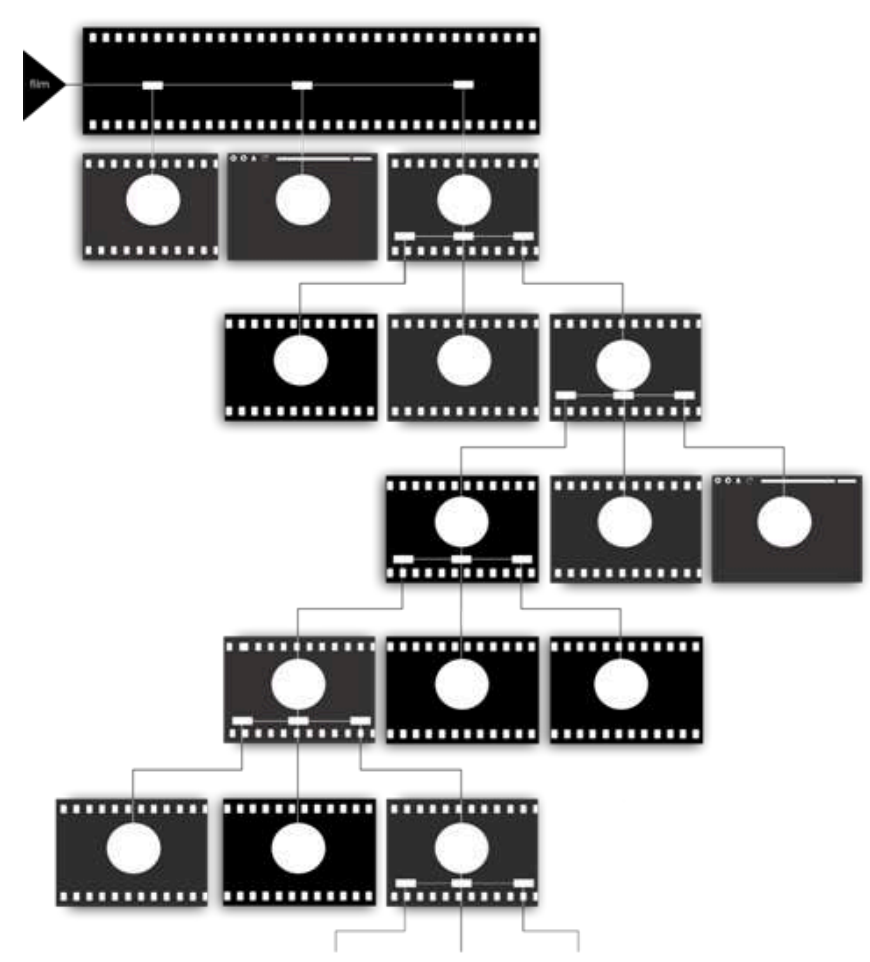

This example of a Transcultural Partnership Media allows navigating an interactive and non-linear movie, in which the audience creates the film while watching it.

\section{(c) Florian Walter}

This does not entail that visual anthropology should be reduced to interface architecture, but rather that postmodern and post-colonial sensibilities demand radical and experimental ethnographies. New forms of visual exploration can allow to grasp detail and context, conflict and hegemony, voices and counter-voices. These case studies offer to anthropological analysis both the potentials and the shortcomings of playing voices and parts against each other, thus allowing different narratives, temporalities and agendas to coexist. This means striving to represent the point of view of the 'subjects' as directly as possible, but also using 'montage' to allow the ethnographer to speak along and give shape to her own argument (Suhr and Willerslev 2013). The visual engagement reviewed here on the one hand disrupt naturalized ways of seeing - whether through digital, spatial, or performative arrangements - but on the other they cultivate the observational sensibility that is the mark of our discipline.

\section{BIBLIOGRAPHY}

Abu-Lughod, Lila, 1986. Writing Against Culture. In Anthropology in Theory - Issues in Epistemology. Henrietta Moore and Todd Sanders, eds. Pp. 466-479. Malden: Blackwell Publishing. 
Berger, John, 1972. Ways of Seeing. London: British Broadcasting Corporation and Penguin Books. Bull, Michael, and Les Back, 2003. The Auditory Culture Reader. Sensory Formation Series. Oxford: Berg Publishers.

Cole, Teju, 2014. "The Atlas of Affect". http://thenewinquiry.com/blogs/dtake/the-atlas-ofaffect/, accessed on July 7, 2014.

Elder, Sarah, 1995. "Collaborative Filmmaking: An Open Space for Making Meaning: A Moral Ground For Ethnographic Film”, Visual Anthropoloy Review, 11(2):94-101.

Favero, Paolo. 2011. "Getting our hands dirty (again): Interactive documentaries and the meaning of images in the digital age", Journal of Material Culture, 18(3): 259-277.

Foucault, Michel, 1975. Surveiller et punir: Naissance de la prison. Paris: Gallimard.

Freedberg, David, 2005. Warburg's Mask: A Study in Idolatry. In Anthropologies of Art. Mariet Westerman (ed.). Pp. 3-25. Williamstown: Clark Institute.

Grasseni, Cristina, 2007 (ed.). Skilled Visions. Between Apprenticeship and Standards. Oxford: Berghahn Books.

Gibson, James Jerome, 1979. The Ecological Approach to Visual Perception, Boston: Houghton Mifflin. Ingold, Tim, 2000. The Perception of the Environment. Essays on Livelihood, Dwelling, and Skill. London: Routledge.

Lapenta, Francesco, 2011. "Geomedia: on location-based media, the changing status of collective image production and the emergence of social navigation systems", Visual Studies, 26 (1):14-24.

Mirzoeff, Nicholas, 2011. The Right to Look: A Counterhistory of Visuality. Durham: Duke University Press.

Ong, Walter Jackson, 1991. The Shifting Sensorium. In The Varieties of Sensory Experience. David Howes, ed. Pp. 47-60. Toronto: University of Toronto Press.

Schneider, Arnd, 2011. Unfinished Dialogues. Notes Toward an Alternative History of Art and Anthropology. In Made to Be Seen. Perspectives on the History of Visual Anthropology. Marcus Banks and Jay Ruby, eds. Pp. 108-135. Chicago: University of Chicago Press.

Walter, Florian, 2012. Medios de comunicación en hermanamiento transcultural. Más allá de la herencia cultural y de la antropología colaborativa. In Espacios mediáticos: cultura y representación en México. Ingrid Kummels, ed. Pp. 347-377. Berlin: Verlag Walter Frey.

Warburg, Aby, 2003. Der Bilderatlas Mnemosyne. In Aby Warburg, 1866-1929. Gesammelte Schriften, vol. 2. Martin Warnke and Claudia Brink, eds. Berlin: Akademie Verlag.

Willerslev, Rane and Suhr, Christian. 2013. "Montage as an Amplifier of Invisibility", in Transcultural Montage, Berghahn Books.

Zumbusch, Cornelia. 2010 “Images of history: Walter Benjamin and Aby Warburg”. In ImageScapes. Studies in Intermediality. Christian J. Emden and Gabriele Rippl, eds. Pp. 117-143. Bern: Peter Lang.

\section{NOTES}

1. See the forthcoming proceedings of the Symposium "Future Past - Cultural Heritage and Collaborative Ethnographic Film Work", Göttingen, 17.5.2010, edited by Beate Engelbrecht and Peter Crawford for Intervention Press. 
2. We would like to thank Peter Crawford for being our panel Discussant. We are particularly grateful to Christian Suhr and Michaela Schäuble for their insightful feedback and intellectual engagement with this project.

3. On Warburg and his relevance to visual anthropology beyond his role as an art historian of the Italian Renaissance, see Schneider (2011) and Freedberg (2005). For a reflection on the relevance of Warburg's Atlas on contemporary forms of art and visuality, and for high definition reproductions of some of Aby Warburg's tables, see Cole (2014): http://thenewinquiry.com/blogs/dtake/the-atlas-of-affect/. 